\title{
Experiences and perceptions of vocational training reported by the 1999 cohort of vocational dental practitioners and their trainers in England and Wales
}

\author{
D. W. Bartlett, ' P. Y. Coward, ${ }^{2}$ R. Wilson, ${ }^{2}$ D Goodsman ${ }^{3}$ and J. Darby ${ }^{4}$
}

Objective To assess the self-reported confidence of vocational dental practitioners (VDPs) in clinical procedures together with vocational trainers' perceptions of the VDPs confidence in the same procedures, immediately after qualification and towards the end of the vocational training year.

Design A questionnaire-based cohort study.

Setting A general practice study carried out in 1999.

Subjects Vocational Dental Practitioners and vocational trainers in England and Wales. Method VDPs and trainers were asked on a single occasion to grade the clinical confidence of the VDP at the beginning and near the end of vocational training as high, satisfactory or low.

Results Questionnaires were sent to 531 VDPs and 555 trainers; 82 per cent of VDPs and trainers responded. Approximately half the VDPs were male and 57 per cent were white, whilst 89 per cent of trainers were male and 81 per cent white. A large proportion of both VDPs and trainers reported low confidence in orthodontics, molar endodontics and surgical extractions at the start of the training year. Towards the end of training, both groups reported improved confidence levels in most clinical procedures. However, a higher proportion of trainers reported low confidence than their VDPs in most clinical procedures at both time points $(\mathrm{p}<0.001)$. VDPs appeared to gain most from experience and training in administration/ management and interpersonal skills.

Conclusion Vocational training appears to satisfy its aim to enhance clinical and administrative confidence.

\footnotetext{
$\mathrm{V}$ ocational training (VT) has been mandatory since October 1993 for newly qualified general dental practitioners who wish to have their name on the dental list, although voluntary schemes had been available for nearly 20 years. The aim of VT is to enhance clinical and administrative competence and to promote high ethical standards and quality of care for patients ${ }^{1}$. Newly qualified graduates gradually assimilate themselves into practice life during this one-year training period with the assistance of a trainer who provides regular tutorials with clinical advice and assistance when

${ }_{1}^{1}$ Division of Conservative Dentistry, ${ }^{2}$ Dental Clinical Research and Education Unit of Guy's King's and St Thomas' School of Dentistry, King's College, London, SE1 9RT; ${ }^{4}$ The Postgraduate Department (VT), Queen Elizabeth Hospital, Woolwich. ${ }^{4}$

${ }^{*}$ Correspondence to Dr D. W. Bartlett, Department of Conservative Dentistry, Floor 25, Guy's Tower, Guy's Hospital, London Bridge, London SE1 9RT.

REFEREED PAPER

Received 25.05.00; Accepted 08.08.00

British Dental Journal 2001; 191: 265-270
}

necessary. In addition, vocational dental practitioners (VDPs) spend a minimum of 30 postgraduate training days at regional training centres. There are two graduate intakes per year, the majority starting in July/August and the remainder in January/February. VT may be undertaken on a full-time basis or part-time over two years, although the vast majority choose to train full time.

Intense competition exists for prospective vocational trainer posts, which are advertised a few months before each scheme commences. The results from a study conducted in 1996 reported that one-third of trainers were re-appointed each year and that 12.5 per cent were women ${ }^{2}$. The trainers are paid a training grant, and the Dental Practice Board reimburses VDPs salaries. The VT schemes are managed locally by competitively selected regional trainers.

Despite being compulsory since 1993 there have been few published reports on the outcome of VT. ${ }^{2,3}$ There is anecdotal evidence to suggest that different views are held by vocational trainers and dental schools on the appropriate level of education and experience needed by newly qualified graduates. $^{3}$ More information is required on VT to assess the perspectives of VDPs and trainers, both immediately after qualification from dental school and at the end of their VT year. The aim of this study was to conduct a questionnaire study to investigate whether the process of VT achieved its aims.

\section{Methods and materials}

The Committee for Vocational Training provided the names and addresses of the VT advisors or postgraduate deans who forwarded the names and addresses of the 1999 cohort of VDPs and trainers. Confidentiality of the responses was assured. The structure of the questionnaire was decided following focus group interviews with 12 VDPs and trainers from a South London regional centre organised by one of the authors. A pilot questionnaire was posted in November 1998 to 49 VDPs and trainers in four regional centres in Southern England. Questionnaires were received from 44 VDPs (90 per cent) and 37 (75 per cent) trainers and as a result of comments and further focus group interviews, a number of changes were made to the structure of the questionnaire.

As this method had been successful in the pilot study, the final questionnaire was distributed by the VT advisors to all VDPs and vocational trainers in England and Wales in April 1999. Completed questionnaires were either forwarded to the authors by the regional advisors or sent individually by the respondents. Follow-up questionnaires were sent out to non-respondents between late April and late July, and the data collection terminated in August 1999.

The structure of the questionnaire is shown in Figure 1. The VDPs and trainers were asked 


\section{EDUCATION vocational training}

the same questions throughout the questionnaire apart from the last section, which was more specific. In the first section, VDPs were asked to grade their clinical confidence in 14 specific clinical skills at two time points (immediately after qualification and near the end of VT) as high, satisfactory or low. The trainers were asked to grade the confidence of the VDP to the same questions. Other sections investigated the VDPs' and trainers' perceptions of the practice and practice staff, the postgraduate release days and an overall assessment of their time during VT.

Paired comparison between the responses from individual trainers and their VDP was carried out using the marginal homogeneity test for differences and Cohen's weighted kappa statistic for agreement.

\section{Results}

Questionnaires were posted in parallel to 555 vocational trainers and 531 VDPs during April 1999. Responses were received from 82 per cent of trainers and 82 per cent of VDPs. In 347 cases it was possible to match individual responses of the trainer to the VDP. Approximately half the VDPs were male (51 per cent), 57 per cent were white and 93 per cent qualified in the UK in 1998. The major proportion of trainers were male (89 per cent), 81 per cent were white and 83 per cent qualified in the UK between 1976 and 1985. More than half did not have any

Part I: Personal information

Name, address, age, date of qualification, qualifications.

\section{Part 2: Clinical confidence}

Level of confidence of VDPs in a number of specific clinical areas (see Table I) graded as high/satisfactory/low.

\section{Part 3: Overall clinical knowledge and skills}

Level of clinical knowledge, practical skills, interpersonal skills, and administration and management graded as good/satisfactory/poor.

\section{Part4: Training environment and programme}

Basic information about the practice and staff.

Trainers availability to offer tutorials and help.

VDPs level of clinical freedom.

The length and usefulness of the induction course.

Provision and value of other teaching, including the day release course:

Assessment of organization, curriculum, VDPs control of curriculum, the value of general dental practioners and dental school staff in providing training.

\section{Part 5: Overall assessment of vocational training}

Trainers were asked to reflect on their own training compared with today s graduates and the suitability of the undergraduate curriculum to train dentist. The VDPs were asked if they would recommend their trainer to succeeding VDPs and their career intentions.

Fig. I The basic structure and content of the questionnaire sent to VDPs and trainers.

postgraduate qualifications (56 per cent). The most common postgraduate qualification held by the trainers was the DGDP.

\section{Reported confidence in clinical skills} Response of VDPs

Table 1 shows the percentage of VDPs reporting high, satisfactory and low levels of confi- dence in specific clinical skills. A large proportion of the VDPs reported low confidence in orthodontics (56 per cent), molar endodontics (47 per cent) and surgical extractions (51 per cent) immediately after qualification, whilst very few reported low confidence in routine periodontics (2 per cent), simple extractions (5 per cent) and the end of vocationd training.

\begin{tabular}{|c|c|c|c|c|c|c|}
\hline \multirow[t]{2}{*}{ Clinical skills } & \multicolumn{3}{|c|}{ Confidence at start of VT } & \multicolumn{3}{|c|}{ Confidence towards end of VT } \\
\hline & high & satisfactory & low & high & satisfactory & low \\
\hline $\begin{array}{l}\text { Orthodontics } \\
\text { Crowns } \\
\text { Planning simple bridges } \\
\text { Molar endodontics } \\
\text { Paediatric dentistry } \\
\text { Dental emergencies } \\
\text { Oral medicine } \\
\text { Routine periodontology } \\
\text { Complete dentures } \\
\text { Partial dentures } \\
\text { Simple extractions } \\
\text { Surgical extractions } \\
\text { Simple treatment plans } \\
\text { Complicated treatment plans }\end{array}$ & $\begin{array}{r}5 \\
12 \\
9 \\
6 \\
23 \\
25 \\
22 \\
49 \\
24 \\
23 \\
44 \\
15 \\
43 \\
6\end{array}$ & $\begin{array}{l}39 \\
63 \\
62 \\
47 \\
59 \\
58 \\
61 \\
49 \\
59 \\
64 \\
51 \\
34 \\
57 \\
60\end{array}$ & $\begin{array}{r}56 \\
25 \\
29 \\
47 \\
18 \\
17 \\
17 \\
2 \\
17 \\
13 \\
5 \\
51 \\
1 \\
33\end{array}$ & $\begin{array}{r}5 \\
49 \\
37 \\
37 \\
44 \\
71 \\
14 \\
62 \\
44 \\
46 \\
86 \\
30 \\
82 \\
22\end{array}$ & $\begin{array}{l}51 \\
50 \\
58 \\
56 \\
53 \\
28 \\
69 \\
36 \\
51 \\
51 \\
14 \\
55 \\
18 \\
76\end{array}$ & $\begin{array}{r}46 \\
1 \\
4 \\
7 \\
3 \\
1 \\
17 \\
2 \\
5 \\
3 \\
0 \\
15 \\
0 \\
2\end{array}$ \\
\hline
\end{tabular}



most confident and 14 least confident

\begin{tabular}{|c|c|c|c|c|c|c|c|c|c|c|c|c|c|c|}
\hline UK DENTAL SCHOOLS & $A$ & B & C & $D$ & $E$ & $\mathrm{~F}$ & G & $\mathrm{H}$ & I & J & K & $\mathrm{L}$ & $M$ & $\mathrm{~N}$ \\
\hline Orthodontics & 1 & 2 & 3 & 4 & 5 & 6 & 7 & 8 & 10 & 9 & 11 & 12 & 13 & 14 \\
\hline Crowns & 4 & 6 & 14 & 13 & 10 & 1 & 2 & 8 & 11 & 9 & 5 & 7 & 11 & 3 \\
\hline Planning simple bridge & 2 & 14 & 4 & 14 & 9 & 10 & 1 & 7 & 3 & 12 & 8 & 11 & 5 & 6 \\
\hline Molar endodontics & 10 & 3 & 4 & 8 & 12 & 5 & 1 & 14 & 2 & 9 & 7 & 13 & 6 & 11 \\
\hline Paediatric dentistry & 2 & 12 & 4 & 1 & 3 & 9 & 8 & 10 & 14 & 7 & 11 & 6 & 5 & 13 \\
\hline Dental emergencies & 2 & 4 & 9 & 1 & 5 & 6 & 3 & 14 & 11 & 8 & 13 & 7 & 12 & 10 \\
\hline Oral medicine & 3 & 1 & 10 & 2 & 4 & 11 & 7 & 14 & 12 & 5 & 9 & 6 & 12 & 8 \\
\hline Routine periodontology & 10 & 4 & 14 & 2 & 13 & 7 & 3 & 12 & 7 & 1 & 6 & 5 & 7 & 11 \\
\hline Complete dentures & 14 & 3 & 5 & 9 & 8 & 6 & 4 & 12 & 1 & 7 & 11 & 10 & 1 & 13 \\
\hline Partial dentures & 14 & 8 & 1 & 4 & 13 & 5 & 6 & 10 & 2 & 7 & 9 & 11 & 2 & 12 \\
\hline Simple extractions & 6 & 1 & 5 & 2 & 13 & 7 & 3 & 11 & 3 & 12 & 9 & 9 & 7 & 14 \\
\hline Surgical extractions & 3 & 1 & 8 & 2 & 4 & 11 & 5 & 10 & 6 & 12 & 9 & 13 & 7 & 14 \\
\hline Simple treatment plans & 10 & 1 & 4 & 7 & 13 & 8 & 9 & 2 & 11 & 5 & 3 & 6 & 11 & 14 \\
\hline Complex treatment plans & 1 & 5 & 3 & 2 & 13 & 10 & 8 & 6 & 11 & 4 & 7 & 9 & 11 & 14 \\
\hline Overall Rank & 4 & 1 & 5 & 3 & 11 & 6 & 2 & 13 & 7 & 8 & 10 & 12 & 9 & 14 \\
\hline $\begin{array}{l}A=\text { Bristol } \\
B=\text { Glasgow } \\
C=\text { King's } \\
D=\text { London }\end{array}$ & \multicolumn{5}{|c|}{$\begin{array}{l}E=\text { Manchester } \\
F=\text { Leeds } \\
G=\text { UMDS } \\
H=\text { Liverpool }\end{array}$} & $\begin{aligned} & =\mathrm{B} \epsilon \\
& =\mathrm{Ne} \\
\mathrm{K} & =\mathrm{Bir} \\
\mathrm{L} & =\mathrm{Ca}\end{aligned}$ & $\begin{array}{l}\text { astle } \\
\text { gham }\end{array}$ & & \multicolumn{6}{|c|}{$\begin{array}{l}M=\text { Dundee } \\
N=\text { Sheffield }\end{array}$} \\
\hline
\end{tabular}

simple treatment plans (1 per cent). Towards the end of VT a smaller proportion of VDPs reported low confidence for all clinical skills, with the exception of oral medicine where low confidence was reported by 17 per cent at both time points. Over 90 per cent of VDPs graded their confidence as high or satisfactory in most clinical skills at this stage, but substantial proportions still claimed low confidence in orthodontics (46 per cent), oral medicine (17 per cent) and surgical extractions ( 15 per cent). There were statistically significant differences observed between the confidence of male and female VDPs with the males reporting higher confidence in making crowns $(\mathrm{p}=0.002)$, simple bridges (0.02), endodontics (0.007) and surgical extractions (0.003). These differences in confidence continued to be reported even at the end of the VT. There were no differences between the ethnic groups.

Table 2 shows the rank score of the 14 UK dental schools according to the selfreported confidence levels (from most confident [1] to least confident [14]) in specific clinical skills of VDPs immediately after qualification.

\section{Response of trainers}

Table 3 shows that a large proportion of

\section{Table 3} Percentage of trainers reporting three levels of confidence of their VDPs in specific clinical skills at the start and towards the end of vocational training

\begin{tabular}{|c|c|c|c|c|c|c|}
\hline \multirow[t]{2}{*}{ Clinical skills } & \multicolumn{3}{|c|}{ Confidence at start of VT } & \multicolumn{3}{|c|}{ Confidence towards end of VT } \\
\hline & high & satisfactory & low & high & satisfactory & low \\
\hline $\begin{array}{l}\text { Orthodontics } \\
\text { Crowns } \\
\text { Planning simple bridges } \\
\text { Molar endodontics } \\
\text { Paediatric dentistry } \\
\text { Dental emergencies } \\
\text { Oral medicine } \\
\text { Routine periodontology } \\
\text { Complete dentures } \\
\text { Partial dentures } \\
\text { Simple extractions } \\
\text { Surgical extractions } \\
\text { Simple treatment plans } \\
\text { Complicated treatment plans }\end{array}$ & $\begin{array}{r}1 \\
5 \\
4 \\
5 \\
12 \\
6 \\
29 \\
17 \\
5 \\
4 \\
18 \\
8 \\
11 \\
2\end{array}$ & $\begin{array}{l}21 \\
50 \\
47 \\
32 \\
70 \\
56 \\
60 \\
72 \\
45 \\
59 \\
60 \\
23 \\
75 \\
29\end{array}$ & $\begin{array}{l}78 \\
45 \\
48 \\
63 \\
18 \\
38 \\
11 \\
11 \\
50 \\
37 \\
22 \\
69 \\
14 \\
69\end{array}$ & $\begin{array}{l}4 \\
35 \\
31 \\
30 \\
42 \\
47 \\
39 \\
45 \\
22 \\
27 \\
65 \\
20 \\
64 \\
13\end{array}$ & $\begin{array}{l}59 \\
62 \\
65 \\
63 \\
57 \\
50 \\
59 \\
53 \\
70 \\
68 \\
33 \\
68 \\
35 \\
76\end{array}$ & $\begin{array}{r}37 \\
3 \\
3 \\
7 \\
1 \\
3 \\
2 \\
2 \\
8 \\
4 \\
2 \\
12 \\
1 \\
11\end{array}$ \\
\hline
\end{tabular}


trainers reported their VDP as having low confidence in orthodontics (78 per cent), molar endodontics (63 per cent), surgical extractions (69 per cent) and complicated treatment plans (69 per cent) immediately after qualification. The major proportion reported high or satisfactory confidence of their VDP for paediatric dentistry (82 per cent), oral medicine ( 89 per cent), routine periodontics ( 89 per cent), simple treatment plans (86 per cent). Towards the end of VT a greater proportion of trainers reported high or satisfactory confidence of their VDP in all clinical skills. However, a substantial proportion still rated their VDP's confidence as low in orthodontics (37 per cent), surgical extractions (12 per cent) and complicated treatment plans (11 per cent), even after a year of VT.

The responses from the trainers were unaffected by either gender or ethnicity. However, trainers did report higher confidence of male VDPs in crowns $(\mathrm{p}=0.001)$, planning simple bridges (0.010), complete dentures (0.021) and surgical extractions (0.024) at the beginning, and in crowns $(\mathrm{p}=0.001)$, planning simple bridges (0.016), paediatric dentistry (0.035) and surgical extractions $(0.047)$ towards the end of VT.

Comparison of responses from VDPs and trainers

Paired comparison between VDPs and trainers was possible for 347 cases (Table 4 ). The responses showed generally poor agreement $(\kappa<0.4)$, with trainers consistently reporting lower confidence levels than their VDP for most clinical skills immediately after qualification $(\mathrm{p} \leq 0.002)$, apart from paediatric dentistry $(\mathrm{p}=0.028)$.

\begin{tabular}{|c|c|c|c|c|c|}
\hline \multirow[t]{2}{*}{ Table 4} & \multicolumn{5}{|c|}{$\begin{array}{l}\text { Paired comparison of responses from each trainee and trainer tested } \\
\text { for differences using marginal homogeneity test [p values] and } \\
\text { agreement using Cohen's weighted kappa statistic [k values] }\end{array}$} \\
\hline & & $\begin{array}{l}\text { Confider } \\
\text { P value }\end{array}$ & $\begin{array}{l}\text { at start of VT } \\
\mathrm{K} \text { value }\end{array}$ & $\begin{array}{l}\text { Confider } \\
\text { P value }\end{array}$ & $\begin{array}{l}\text { towards end of VT } \\
\mathrm{K} \text { value }\end{array}$ \\
\hline \multicolumn{2}{|c|}{$\begin{array}{l}\text { Orthodontics } \\
\text { Crowns } \\
\text { Planning simple bridge } \\
\text { Molar endodontics } \\
\text { Paediatric dentistry } \\
\text { Dental emergencies } \\
\text { Oral medicine } \\
\text { Routine periodontology } \\
\text { Complete dentures } \\
\text { Partial dentures } \\
\text { Simple extractions } \\
\text { Surgical extractions } \\
\text { Simple treatment plans } \\
\text { Complex treatment plans }\end{array}$} & $\begin{aligned}<0.001 \\
<0.001 \\
<0.001 \\
<0.001 \\
0.028 \\
<0.001 \\
0.002 \\
<0.001 \\
<0.001 \\
<0.001 \\
<0.001 \\
<0.001 \\
<0.001 \\
<0.001\end{aligned}$ & $\begin{array}{l}0.168 \\
0.272 \\
0.108 \\
0.117 \\
0.179 \\
0.186 \\
0.105 \\
0.132 \\
0.147 \\
0.052 \\
0.183 \\
0.413 \\
0.016 \\
0.096\end{array}$ & $\begin{array}{r}0.114 \\
<0.001 \\
0.093 \\
0.196 \\
0.870 \\
<0.001 \\
<0.001 \\
<0.001 \\
<0.001 \\
<0.001 \\
<0.001 \\
0.132 \\
<0.001 \\
<0.001\end{array}$ & $\begin{array}{l}0.270 \\
0.188 \\
0.134 \\
0.243 \\
0.222 \\
0.009 \\
0.129 \\
0.153 \\
0.317 \\
0.132 \\
0.120 \\
0.318 \\
0.047 \\
0.095\end{array}$ \\
\hline
\end{tabular}

Similarly, statistically significant disagreement was observed between VDPs and trainers at the end of VT in many clinical skills. However, there was no statistically significant difference in perception of the VDPs confidence in orthodontics, planning simple bridges, molar endodontics, paediatric dentistry or surgical extractions between the two groups at this stage.

\section{Overall clinical knowledge and general practice skills}

The majority of the VDPs and their trainers rated the VDPs clinical knowledge, practical and interpersonal skills as either good or satisfactory both at the beginning and towards the end of VT (Tables 5 and 6). However, 70 per cent of both VDPs and trainers rated the VDPs administration and management ability as poor at the start of VT. By the end of the training, only 6 per cent of VDPs and 8 per cent of trainers rated this aspect as poor.

\section{Training environment and programme}

The majority of VDPs reported that the availability of the trainer for help and advice was good or satisfactory. Most VDPs (76 per cent) stated they had weekly tutorials from their trainer, although 17 VDPs received less than three tutorials during the year. Most VDPs and their trainers reported that specific teaching related to improving clinical knowledge was given. However, 35 per cent of VDPs and 10 per cent of trainers reported that no teaching of interpersonal skills was provided.

The induction course, a specific requirement of VT, was reported as having occurred in the majority of cases, but nearly 20 per cent of VDPs claimed it was absent. Of those who received the course, the majority considered it worthwhile. VDPs

\begin{tabular}{|c|c|c|c|c|c|c|c|}
\hline \multirow[t]{3}{*}{ Table 5} & \multicolumn{7}{|c|}{$\begin{array}{l}\text { Percentage of VDPs reporting three levels of confidence in clinical knowledge and general skills at the stari } \\
\text { and towards the end of vocational training }\end{array}$} \\
\hline & & \multicolumn{3}{|c|}{ Confidence at start of VT } & \multicolumn{3}{|c|}{ Confidence towards end of VT } \\
\hline & & high & satisfactory & low & high & satisfactory & low \\
\hline \multicolumn{2}{|c|}{$\begin{array}{l}\text { Clinical knowledge } \\
\text { Practical Skills } \\
\text { Interpersonal skills } \\
\text { Administration/management }\end{array}$} & $\begin{array}{r}34 \\
17 \\
44 \\
3\end{array}$ & $\begin{array}{l}63 \\
78 \\
50 \\
27\end{array}$ & $\begin{array}{r}3 \\
5 \\
6 \\
70\end{array}$ & $\begin{array}{l}80 \\
82 \\
84 \\
32\end{array}$ & $\begin{array}{l}20 \\
18 \\
16 \\
62\end{array}$ & $\begin{array}{l}0 \\
0 \\
0 \\
6\end{array}$ \\
\hline
\end{tabular}



skills at the start and towards the end of vocational training

\begin{tabular}{|l|c|c|c|c|c|c|}
\hline & \multicolumn{3}{|c|}{ Confidence at start of VT } & \multicolumn{3}{c|}{ Confidence towards end of VT } \\
\hline & high & satisfactory & low & high & satisfactory \\
\hline Clinical knowledge & 36 & 56 & 8 & 81 & 18 & 1 \\
\hline Practical skills & 16 & 63 & 21 & 68 & 30 & 1 \\
\hline Interpersonal skills & 31 & 46 & 23 & 66 & 30 & 4 \\
\hline Administration/management & 2 & 28 & 70 & 29 & 63 & 8 \\
\hline
\end{tabular}

considered that most staff within the practice were helpful and that they were given reasonable flexibility in ordering specific materials.

Most VDPs and trainers thought that the structure of the postgraduate days, their control of the course and the proportion of 'hands-on' teaching was good or satisfactory. However, 17 per cent of VDPs thought that the postgraduate release days were not a useful exercise and 30 per cent claimed that they had either poor or no control over the structure of these days. Both university teachers and general practitioners reportedly gave good or satisfactory levels of teaching, but VDPs considered that the general practitioners were better at teaching topics related directly to general dental practice.

\section{Overall assessment of vocational training}

Most trainers (60 per cent) rated the undergraduate curriculum as good or satisfactory in preparing VDPs for general practice and 99 per cent thought that VT was effective. When the trainers were asked to reflect on how the VDPs' overall confidence compared with their own confidence at qualification, 70 per cent thought that the current VDPs compared well. The majority of VDPs (89 per cent) reported that they would recommend their trainer to future trainees. Most VDPs (84 per cent) felt that the workload was appropriate for their future needs and rated their clinical freedom as good (73 per cent).

\section{Discussion}

The system of asking the regional organisers to distribute the questionnaires worked well and, together with the involvement of Committee for Vocational Training, resulted in a high level of response. It was recognised that a questionnaire survey provides a limited qualitative assessment of subjective perceptions, but it was considered to be the only practical means to investigate the large numbers of subjects in this cohort. The involvement of VDPs and trainers in structuring the questionnaire was particularly useful and prevented the the inclusion of preconceived ideas about VT.

The reliance on assessment of confidence in clinical skills was a compromise as it was considered more difficult for VDPs or their trainers to assess clinical ability in the absence of a gold standard. The inclusion of questions relating to confidence both at the start and near the end of VT in the same questionnaire was considered the best way to achieve comparisons of qualitative data for responses made on a subjective basis. Competence could not be assessed within the confines of this study and consequently confidence was used as the assessment. However, confidence does not always imply competence in a particular skill, someone can be very confident but may be incompetent. At qualification, graduates are assessed as being competent, therefore, whether VT should be involved in further competence evaluation in specific skills may be contentious and beyond the scope of this paper. Further research could target those skills in which VDPs were generally perceived to be lacking confidence, such as endodontics and surgical. Other research could investigate how past VDPs perceived the success of VT in achieving its aims $2-3$ years after they completed their VT year.

Silversin et al in $1974^{4}$, Kay \& Blinkhorn in $1987^{5}$, and Murray et al in $1999^{3}$ have reported previously that VDPs suggested that they needed more experience in orthodontics and surgical extractions. Similarly, Brookman ${ }^{6}$, Kay and Blinkhorn ${ }^{5}$ reported a lack of teaching and associated low confidence in molar endodontics and advanced crown and bridge during undergraduate education. VDPs and trainers were not asked to rate confidence in 'advanced crown and bridge' in the present study, as this might now be regarded as a specialist area. However, the present results are in agreement with these previous reports with regard to orthodontics, surgical extractions and molar endodontics. The low level of confidence in these areas appears not to have been addressed in recent decades. It is possible that dental schools take the attitude that confidence in all these skills is more effectively developed in a general practice arena, and have concentrated on providing a basic understanding of the principles alone. Confidence in most of these clinical skills does markedly improve towards the end of VT, but it is evident that confidence in orthodontics remains low even after a year in practice. The fact that one-third of VDPs reported low confidence in making complicated treatment plans at the start of VT is not unexpected, but only 2 per cent remained at this level by the end.

Males appeared to be more confident in a variety of clinical procedures at the start and the end of the training year. It may be that males report more confidence but are not necessarily more competent. However, it is significant that the trainers' perceptions of the VDPs confidence confirmed some of the differences between gender at both the beginning and towards the end of VT. This was particularly noticeable for planning simple bridges and surgical extractions. A 
difference in confidence reported by VDPs was also recognisable between the dental schools. Although VDPs from all schools reported widely varying levels of confidence related to different clinical procedures, some schools ranked higher than others in more than one area. This difference may reflect teaching performance or different skills developed by the schools. However, the present results only indicate that some schools produce more confident students.

The different ethnic and gender mix of VDPs and their trainers may reflect changes in the intake of dental schools that have occurred in recent years. There are no published data for ethnic and gender mix on the GDC register but this study reports the findings based on this study sample. Most trainers were male and white whilst the VDPs had a broader ethnic and gender mix. It is anticipated that in the future this will change, as today's VDPs become tomorrow's trainers.

A difference between the views of the VDPs and their trainers might have been predicted at the start of the project. First, the low scores reported by trainers for VDPs immediately after graduation may have been influenced by a desire to demonstrate the value of their training. Second, they may have set higher standards than the VDPs related to their own confidence in dental practice gained through years of experience.

Despite reporting low confidence of VDPs at the start of VT, the majority of trainers considered their VDP to have a good or satisfactory level of clinical knowledge and practical skill. These results sug- gest that trainers recognise that undergraduates have received a good general dental education, but lack confidence in specific areas. However, 40 per cent of trainers in this study considered the undergraduate curriculum poor in preparing dentists and other anecdotal evidence points towards trainers having a low opinion of undergraduate training as a preparation for general dental practice ${ }^{7}$. Although such responses from trainers may be biased, the combined results of VDPs and trainers in this study suggest some areas of clinical skill where dental schools might reflect on the adequacy of their training. On the other hand, undergraduate educators might justifiably claim that developing clinical confidence is what VT was designed to do.

There was some disagreement between VDPs and trainers on the presence of teaching in interpersonal skills during the VT year. The difference may have arisen as a result of VDPs expectation of formal training, whereas trainers might argue that they teach by example. Despite this, both the VDPs and their trainers thought that they had achieved considerable improvement in both interpersonal and administration and management skills towards the end of the VT year, although there was some disagreement on the level achieved. VDPs appeared satisfied with other elements of practice and postgraduate release days and this undoubtedly reflects the careful selection of trainers by the regional organisers with the assistance of the postgraduate deans. Vocational trainers make an important contribution to the education of dentists and as such should be encouraged to participate in courses aimed to improve their teaching skills. Most postgraduate regions will include such teaching as part of their 'training the trainers' courses, and the requirement for such training should be debated alongside the need for more formal assessment of VT.

It would appear that both VDPs and trainers thought that, in general, VT achieved its aim of enhancing the confidence and skills of newly qualified dentists.

The authors would like to recognise the assistance with funding and construction of this study from the Committee for Vocational Training (CVT) and the National Centre for Continuing Professional Education for Dentists (NCCPED).

1. CVT. Aims and Objectives for Vocational Training. 2000; http://www.eastman.ucl.ac.uk/ $\sim$ shall/whatsvt 2 .html.

2. Bartlett D W, Coward P Y, Goodsman D, Darby J. Experience of undergraduates from three London dental schools and trainers from the south east of England on interviews for vocational training in 1996. Br Dent J 1997; 183: 284-288.

3. Murray F J, Blinkhorn A S, Bulman J S. An assessment of the views by recent graduates on their undergraduate course. Eur J Dent Education 1999; 3: 3-9.

4. Silversin J B, Shafer S M, Smales F C, Sheiham A. British dentists and final year British and United States students' opinions about their undergraduate training. Br Dent J 1974; 137: 161-168.

5. Kay E J, Blinkhorn A S. Scottish dental students' views on their undergraduate training. Br Dent J 1987; 162: 317-319.

6. Brookman D J. Vocational trainee's views of their undergraduate endodontic training and their vocational training experience. Int Endo J 1991; 24: 178-186.

7. Firestone H, Mackie I C. Graduate training expectations [letter]. Br Dent J 1999; 187: 4. 